\title{
A Novel Compact Microwave Radiometric Sensor to Noninvasively Track Deep Tissue Thermal Profiles
}

\author{
Paolo F. Maccarini \\ Duke University \\ Ankur Shah \\ Duke University \\ Sharmila Y. Palani \\ Duke University \\ Donald V. Pearce \\ Duke University \\ Madhurima Vardhan \\ Duke University
}

See next page for additional authors

Follow this and additional works at: https://jdc.jefferson.edu/radoncfp

Part of the Radiology Commons

\section{Let us know how access to this document benefits you}

\section{Recommended Citation \\ Proceedings of 2015 European Microwave Week}

This Article is brought to you for free and open access by the Jefferson Digital Commons. The Jefferson Digital Commons is a service of Thomas Jefferson University's Center for Teaching and Learning (CTL). The Commons is a showcase for Jefferson books and journals, peer-reviewed scholarly publications, unique historical collections from the University archives, and teaching tools. The Jefferson Digital Commons allows researchers and interested readers anywhere in the world to learn about and keep up to date with Jefferson scholarship. This article has been accepted for inclusion in Department of Radiation Oncology Faculty Papers by an authorized administrator of the Jefferson Digital Commons. For more information, please contact: JeffersonDigitalCommons@jefferson.edu. 


\section{Authors}

Paolo F. Maccarini, Ankur Shah, Sharmila Y. Palani, Donald V. Pearce, Madhurima Vardhan, Paul R. Stauffer, Dario B. Rodrigues, Sara Salahi, Tiago R. Oliveira, Doug Reudink, and Brent W. Snow 


\section{A Novel Compact Microwave Radiometric Sensor to Noninvasively Track Deep Tissue Thermal Profiles}

\author{
Paolo F. Maccarini, Ankur Shah, Sharmila Y. Palani, \\ Donald V. Pearce, Madhurima Vardhan \\ Dept. of Biomedical Engineering, Duke University \\ Durham, NC - USA \\ paolo.maccarini@duke.edu
}

\author{
Paul R. Stauffer and Dario B. Rodrigues \\ Radiation Oncology Dept., Thomas Jefferson University \\ Philadelphia, PA - USA \\ paul.stauffer@jefferson.edu, dario.rodrigues@jefferson.edu
}

\author{
Sara Salahi \\ ANSYS, Inc \\ Irvine, CA - USA \\ sara.louie@ansys.com
}

\begin{abstract}
Drawing from space technology to measure star temperature, we developed a noninvasive sensor to passively track thermal profiles in tissues well below the skin $(>5 \mathrm{~cm})$. Ultra-low noise amplifiers combined with ultralow-loss switches in the 1$2 \mathrm{GHz}$ band produce a high sensitivity multiband microwave radiometer. Due to the complex multilayer anatomy of human head, multiple sensing bands are needed to reconstruct the temperature of deep brain tissue. This is achieved by using a digitally controlled filter bank. To study its accuracy, the sensor was calibrated and tested in a multilayer phantom model of the human head with differential scalp and brain temperatures. Results of phantom testing showed that calculated radiometric equivalent brain temperature agreed within $0.4^{\circ} \mathrm{C}$ of measured temperature when circulating homogenized brain phantom was lowered $10^{\circ} \mathrm{C}$ and returned to original temperature $\left(37^{\circ} \mathrm{C}\right)$, while scalp was maintained constant over a 4.6-hour experiment. Feasibility of clinical monitoring was assessed in a pediatric patient during a hypothermic heart surgery. Over the 2-hour surgery, the radiometric sensor tracked within $1^{\circ} \mathrm{C}$ of rectal and nasopharynx temperatures, except during rapid cooldown and heatup periods when brain temperature deviated $2-4^{\circ} \mathrm{C}$ from slower responding core temperature surrogates. In summary, the sensor demonstrated long term stability and sensitivity sufficient for accurate monitoring of volume average brain temperature to assist rapid recovery from hypothermic surgical procedures.
\end{abstract}

Keywords-Microwave Radiometry; Ultra Low Noise Amplifier; Tissue Temperature; Noninvasive Sensor.

\section{INTRODUCTION (HEADING 1)}

Hypothermia, where body core temperature drops below $36^{\circ} \mathrm{C}$, can triple the risk of morbid myocardial outcomes following surgery [1], triple the risk of surgical wound infection

NIH - 1R21GM111560-01, NIH - 1R21 DK092912 and NIH - R43 GM105109R21 sponsored the research presented here.

\author{
Tiago R. Oliveira \\ Institute of Physics, University of São Paulo \\ São Paulo-BRAZIL \\ tiagor.olivei@gmail.com
}

\author{
Doug Reudink \\ ThermImage, Inc. \\ Salt Lake City, UT - USA \\ dougr@thermimage.com
}

\author{
Brent W. Snow \\ Dept. of Surgery and Urology, University of Utah \\ Salt Lake City, UT - USA \\ brent.snow@hsc.utah.edu
}

[2,3], increase blood loss [4-6], increase transfusion requirements [4-6], prolong surgical recovery [7], and extend the duration of hospitalization [2]. It is therefore imperative that anesthesiologists monitor and effectively manage core temperature. For rapid recovery to good health, reestablishing normothermic temperature of the internal organs is essential. Although brain is the most critical temperature sensitive tissue [8], core temperature, currently considered the temperature of internal body organs, can differs significantly from brain. In fact, current thermometry devices typically measure only intracavitary surrogates of body temperature that do not accurately reflect core temperature of the deep lying organs, especially brain. Each of these surrogate core temperature measurements has inherent problems with probe placement, time delays in reading changing body temperature, and/or are objectionably invasive [9,10].

Readily available non-invasive measurements include axillary and forehead surface thermometers which vary with contact, movement, perspiration, and environment. Such surface measurements produce an unreliable prediction of temperature deep in the body [11,12]. Infrared thermography can noninvasively sense thermal energy emitted from tissue close to the surface, but those measurements do not reflect temperatures deep in the body. In particular, temperature measurement of the temporal artery takes advantage of high perfusion in the region which could reflect core temperature, but calibration of such readings is highly dependent on skin emissivity, perspiration, and environment, which vary greatly for typical operating room conditions $[11,12]$. Infrared measurements of the tympanic membrane have the potential to correlate with deep body temperature, but in clinical practice are less reproducible due to the tortuous anatomy of ear canal and cerumen presence $[11,13]$. 
Invasive measurements of core temperature are generally accomplished either with intracavitary devices like rectal, Foley, nasopharyngeal, endotracheal and esophageal probes, or with temperature sensors placed interstitially in the pulmonary artery [11,13-15]. Placement of internal temperature probes is uncomfortable, may require sedation or anesthesia, and is not without risk. The accuracy of these invasive probes depends on many factors $[11,16]$. For instance, the position of nasopharyngeal temperature probes placed under anesthesia is uncertain and the amount of mouth breathing or endotracheal tube air leakage affects the readings. Rectal probes work best if the probe tip is located against the perfused rectal wall rather than inside feces, but this is difficult to ensure and if partially insulated from the rectal wall there may be significant delays in reading surrounding body temperature. Accuracy of bladder thermometry via a Foley catheter depends on urine production, bladder volume and probe location within the bladder. Like rectal measurements, Foley probes generally exhibit significant time delays in reading organ temperature, especially when the temperature is changing rapidly from intentional external heating or cooling. Although highly invasive, the most reliable "core" temperature probe is a pulmonary artery catheter which is passed through a vein into and through the right atrium of the heart into the pulmonary artery [13]. However, only severely ill or high-risk surgical patients warrant pulmonary artery monitoring due to the potential risks of such an invasive procedure. And because of their status, these patients often receive large amounts of room temperature IV fluids as well as refrigerated blood products that reduce the accuracy of this core temperature reading. Still, the brain temperature is not necessary equal to the core temperature and brain invasive probes (Licox System, Plainsboro, NJ, USA) are affected by the inflammatory response and only measure a single location.

There is an urgent need for a brain-specific volumetric temperature measurement. Microwave (MW) radiometry is a non-invasive technique that collects thermal radiation (electromagnetic noise) emitted in the MW frequency spectrum by any material above absolute zero temperature. The thermal radiation is received by an antenna and converted, with proper calibration, into a measure of absolute temperature of tissues sensed by a weighted average of its radiation/receive pattern [1012]. This technique contrasts with infrared thermometry that collects thermal radiation at higher frequencies $(0.3-430 \mathrm{THz})$, where photons travel only a few millimeters through skin. There have been many reports of medical applications of MW radiometry, including the detection of breast cancer [13], monitoring and control of superficial and deep hyperthermia applicators [14-17], measurement of brain temperature in infants [10] or adults [18], vesicoureteral reflux detection in young children $[19,20]$ and more recently monitoring of brown fat metabolism [21]. In the particular case of monitoring adult brain temperature, there are no reports to our knowledge of an antenna small enough to conform to the human head during prolonged surgery; present a stable reading over several hours; and offer an accuracy of $0.5^{\circ} \mathrm{C}$, which is the smallest difference that has been associated with hypothermia-induced complications [8].

This investigation reports preliminary testing of a novel noninvasive core temperature thermometer that uses a small microwave radiometric sensor on the skin surface to measure thermal radiation emitted from tissue in the 1.1-1.6 GHz band Unlike infrared radiation which travels less than a centimeter to the surface, thermal emissions in the microwave range travel many centimeters through tissue. The amount of microwave energy received by a surface antenna increases with increasing tissue temperature and may be used to quantify deep tissue temperature. We choose to monitor temperature inside the brain [17] rather than alternative sites due to the critical nature of this organ and its central role in thermoregulation $[8,16]$. The purpose of this study is to characterize the sensitivity and accuracy of a new radiometric thermometer for long-term monitoring of core temperature in brain. To demonstrate the performance of the device, we built a realistic phantom model of the human head with separate brain and scalp regions consisting of tissue equivalent liquids circulating at independent temperatures on either side of an intact skull. This life size multilayer model of the human head allows simulation of differential surface and deep tissue temperatures. Thus, the quantification of radiometer sensitivity to changes in brain is independent of scalp and operating room temperatures.

\section{INSTRUMENT DESIGN}

\section{A. System Diagram}

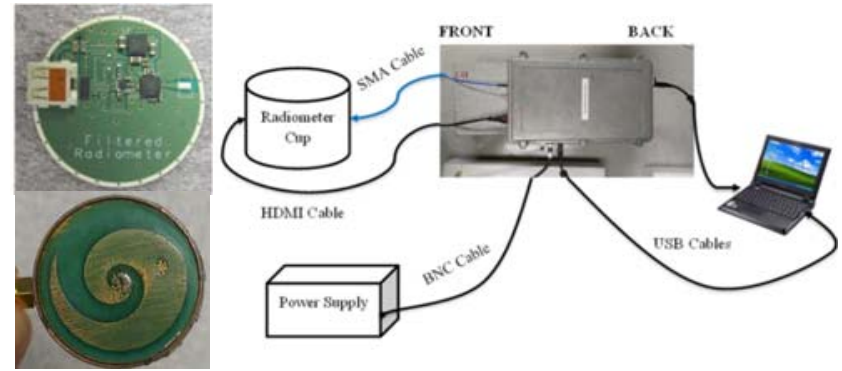

Fig. 1. $2.5 \mathrm{~cm}$ dia PCB radiometer with I stage amplification, filters, and temperature reference switches (top left) on back of log spiral antenna inside Electromagnetic Interference (EMI) shielded enclosure (bottom left), and schematic of radiometer system (right).

The key innovation of this project is the integration of two critical components: a small $(2.5 \mathrm{~cm}$ dia $)$ receive antenna optimized with electromagnetic simulation software (HFSSTM Ansys, Canonsburg, PA, USA) for deep penetration into the human head, and a high gain 1.1-1.6 GHz microwave radiometer with miniature printed circuit chip components mounted on the back of the antenna sensor. A novel dual matched amplifier radiometer circuit $[2,7]$ provides enhanced sensitivity by maintaining direct connection of receive antenna to the first amplification stage and provides a time sequenced comparison to an internal temperature reference for long-term stable calibration [18]. Signals from the temperature references are switched and amplified through the second matched amplifier rather than time sequencing all reference and unknown signals through a single amplifier. By placing the first stage amplification directly on the back of the antenna, this eliminates the coaxial feedline which typically introduces losses and EMI into the signal at the most critical low signal level received from tissue. Further amplification, multiband filtering, signal detection, and logic control of the RF switches and thermistor readings are accomplished with circuitry in a second small chassis (6" $\mathrm{x} 9$ " $\mathrm{x} 3$ ") which is connected to the radiometer sensor 
assembly with a micro-HDMI cable and ultra-lowloss, high shielding 0.086" coaxial cable (TempFlex 086-2201, Elvissa RF Cable Assemblies Inc). The calibration, running averages, signal processing of drift compensation from reference values, logic control, and conversion to temperature are performed in a Labview program running on a laptop computer. The entire sensor package is contained in a lightweight and low profile 2.8 $\mathrm{cm}$ dia by $1.5 \mathrm{~cm}$ height assembly held in place over skin with EMI shielding adhesive patch and/or elastic strap (Fig. 2).
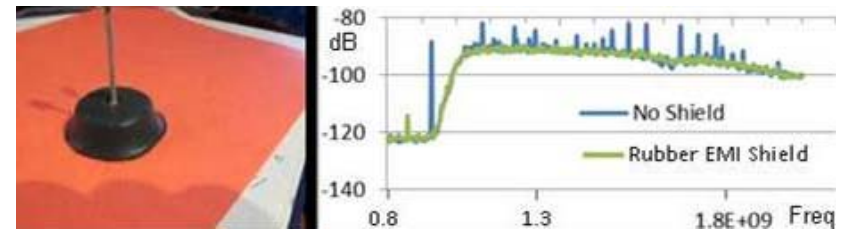

Fig. 2. The sensor is encapsulated in a black conductive silicone rubber shield to mitigate EMI (left). The EMI shielding performance of a single layer shield significantly mitigate EMI in the radiometric sensing band (right).

\section{B. Heterogeneous Phantom Testing}

We tested and calibrated the radiometric sensor in realistic heterogeneous multilayer tissue models with known temperature distributions. We constructed a realistic phantom model of a lifesize human head with realistic tissue-equivalent scalp, skull and brain tissue compartments. The literature reports a range of dimensions for the constituent tissues of the human head [19], with scalp consisting of skin that ranges from $3 \mathrm{~mm}$ (forehead) to $8 \mathrm{~mm}$ (occipital region) thick and subcutaneous fat and fibrous tissues from $4 \mathrm{~mm}$ to $7 \mathrm{~mm}$ thick overlying the skull. To generate a realistic physical model for radiometric measurements, a de-identified human brain CT scan dataset was analyzed with tissue segmentation software (Avizo, FEI Visualization Sciences Group, Burlington MA, USA) to establish appropriate values for the thickness of scalp, bone, and brain tissues. Measurements from this CT dataset showed that the scalp (skin/fat/muscle) varied from $4.2 \mathrm{~mm}$ (forehead) to 10 $\mathrm{mm}$ (temporal lobe) thick and the skull bone was $6.7 \mathrm{~mm}$ thick in both regions. These measurements are in general agreement with the literature [19]. The distance from the forehead surface to the ventricle deep in brain was $45.5 \mathrm{~mm}$ for this patient. Based on these tissue dimensions, an experimental model of the human head was constructed from tissue mimicking phantom mixtures for scalp and brain tissues that fit around an artificial human skull (Life Size Skull, www.anatomywarehouse.com) having geometry and dielectric properties similar to skull bone. A photograph of the experimental model is shown in Fig. 3. To model the thermodynamics of scalp, which is a mixture of skin, fat and muscle tissues, an adjustable thickness $(6-16 \mathrm{~mm})$ compartment was sealed against the outer surface of the skull and filled with temperature-controlled distilled water $\left(\varepsilon_{r}=74.2\right.$, $\sigma=0.28$ at $1.35 \mathrm{GHz}$ ) that was circulated at $1.71 / \mathrm{min}$ flow rate to maintain a homogeneous stable scalp temperature. To simulate brain, a mixture of ethylene glycol, water and $\mathrm{NaCl}$ was used to approximate the electrical properties of mixed grey and white matter $\left(\varepsilon_{r}=52.43, \sigma=1.45 \mathrm{~S} / \mathrm{m}\right.$ at $\left.1.35 \mathrm{GHz}\right)$. Dielectric properties of the phantom tissue components were characterized using a coaxial dielectric properties probe (E85070C, Agilent Technologies, Santa Rosa CA, USA) connected to a network analyzer (E5071C, Agilent Technologies) and adjusted to conform with Cole-Cole data for the respective biological tissues [20]. The liquid brain phantom was circulated vigorously $(\sim 3 \mathrm{l} / \mathrm{min})$ with a peristaltic pump through a latex balloon that filled the interior of the skull, and temperature was controlled with a heat exchanger to mimic changes in deep brain temperature resulting from anesthesia and subsequent thermoregulatory responses. Temperatures of scalp and brain were controlled independently to provide a range of different surface: deep temperature gradients typical of various surgical procedures.
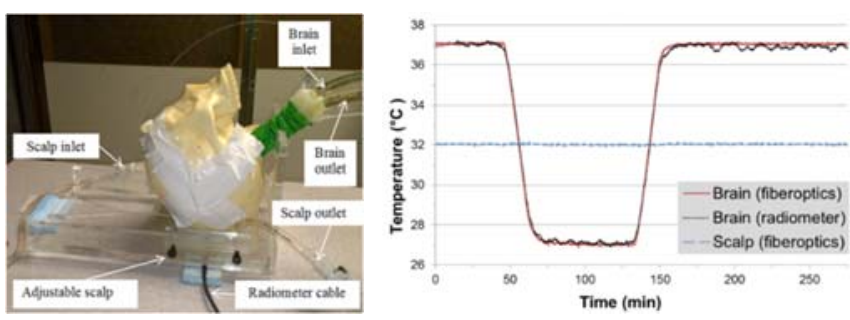

Fig. 3. Life size human head model with circulating temperature controlled scalp tissue equivalent medium at bottom and brain tissue equivalent medium circulating through a balloon filling the interior of the skull at different controlled temperatures. The radiometer sensor located under the variable thickness layer of scalp tissue at bottom of model (left). Temperatures were recorded with fiberoptic sensors at the scalp (blue), brain (red), and corresponding radiometric signal is shown in black (right).

These temperature gradients were used for calibration of the temperature conversion algorithm in order to distinguish volume averaged brain temperature from cooler and warmer scalp, and for subsequent testing of radiometer performance. The radiometric signal was smoothed using a $200-400$ point moving median calculation in order to eliminate the short-term fluctuations from EMI environmental noise. Radiometer accuracy was quantified in terms of measurement error, defined by the absolute difference between brain temperatures measured by the fiberoptic probe and calculated from radiometric received power. A statistical analysis of the difference was implemented for each segment of the experiment: i) initial steady state with $37^{\circ} \mathrm{C}$ brain and $32^{\circ} \mathrm{C}$ scalp, ii) rapid brain cooling, iii) steady state plateau at $27^{\circ} \mathrm{C}$ brain temperature, iv) rewarming, and v) final steady state plateau with brain back to $37^{\circ} \mathrm{C}$.

\section{Clinical Testing}

In order to demonstrate the clinical feasibility of this radiometric monitoring approach, an Institutional Review Board approved protocol was initiated to monitor brain temperature in pediatric patients during heart surgery. For initial proof of concept, a radiometric sensor was placed on the temple of a seven-year-old male patient - undergoing ventriculoseptal defect repair surgery - to radiometrically measure brain temperature. As is typical in this procedure, body temperatures were charted with $1^{\circ} \mathrm{C}$ precision at approximately $15 \mathrm{~min}$ intervals, providing a general reference for changes in body core temperature during the two-hour surgical procedure. Skin surface was measured with a thermistor embodied in the radiometer and deep brain temperature was monitored continuously with the radiometric sensor throughout the $120 \mathrm{~min}$ surgical procedure, while the patient's whole body was cooled approximately $6^{\circ} \mathrm{C}$ and subsequently rewarmed. Radiometric brain temperature was compared with skin temperature under 
the sensor and with nasopharyngeal and rectal core data recorded manually by an anesthesiologist during the procedure.
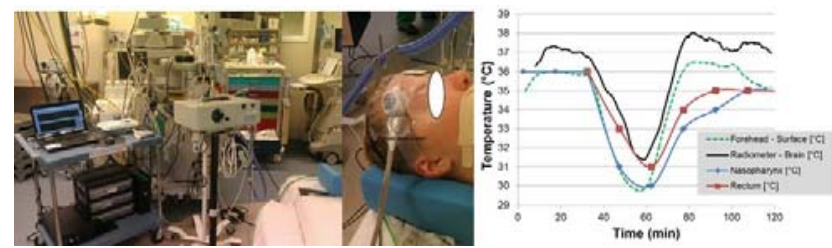

Fig. 4. Equivalent brain temperature (black) from 400pts median calculations of raw radiometer readings during surgery of pediatric patient, correlated with rectal (red) and nasopharyngeal (blue) core temperature measurements and skin surface just under the radiometer sensor (green).

\section{DISCUSSION AND CONCLUSIONS}

A non-invasive core temperature thermometer has been developed based on a single band 1.1-1.6 GHz microwave radiometer with progressive calibration technology. The accompanying radiometric sensor includes a dual matched ultralow noise pre-amplifier with internal temperature compensation and filtering, and a tapered log spiral antenna embedded in a lightweight and low profile $2.8 \mathrm{~cm}$ diameter by $1.5 \mathrm{~cm}$ high EMI shielded assembly. Experimental measurements were performed in a full-scale multilayer tissue model of the human head to confirm our ability to sense small temperature changes in deep brain, independent of the temperatures of overlying scalp and skull. This phantom study shows that a non-invasive microwave radiometer has the ability to track changes in brain temperature with an accuracy better than $0.5^{\circ} \mathrm{C}$ over the long periods typical of open heart bypass surgery. Radiometric measurements of pediatric brain temperature during a two-hour surgical procedure demonstrate a loose correlation with core temperature measurements in rectum and nasopharynx, but appear to respond more quickly to changes in circulating blood temperature during patient rewarming. These data point to the clinical utility of this radiometric monitoring approach for rapid and safe non-invasive determination of critical brain temperature. This non-invasive assessment of volume-averaged brain core temperature should become a valuable tool to assist thermal management of patients undergoing surgery or recovery from hypothermic events.

\section{ACKNOWLEDGMENT}

The authors would like to recognize significant contributions from a diverse team of collaborators from the University of Tromso, University of Rome Tor Vergata, University of L'Aquila, and University of Utah, as well as the encouragement and financial support from Doug Turnquist at Thermimage Inc. We would like to acknowledge the support of related technology development in several NIH grants, NIH-1R21GM111560-01, NIH-1R21 DK092912 and NIH-R43 GM105109R21, as well as software and hardware support from Ansys Corp, Agilent Technologies, National Instruments and Aprel Corp.

\section{REFERENCES}

[1] Frank SM, Fleisher LA, Breslow MJ, et al. Perioperative maintenance of normothermia reduces the incidence of morbid cardiac events. A randomized clinical trial. JAMA. 1997;277(14):1127-34.
[2] Kurz A, Sessler DI, Lenhardt R. Perioperative normothermia to reduce the incidence of surgical-woundinfection and shorten hospitalization. $\mathrm{N}$ Engl J Med. 1996;334(19):1209-15.

[3] Polderman KH. Mechanisms of action, physiological effects, and complications of hypothermia. Crit Care Med. 2009;37:S186-S202.

[4] Schmied H, Kurz A, Sessler DI, et al. Mild hypothermia increases blood loss and transfusion requirements during total hip arthroplasty. Lancet. 1996;347(8997):289-292.

[5] Winkler M, Akça O, Birkenberg B, et al. Aggressive warming reduces blood loss during hip arthroplasty. Anesth Analg. 2000;91(4):978-84.

[6] K Arunachalam, PF Maccarini, V De Luca, F Bardati, BW Snow, PR Stauffer. Modeling the Detectability of Vesicoureteral Reflux using Microwave Radiometry. Phys Med Biol 2010;55(18):5417-35. PMCID:2972589

[7] Klemetsen O, Birkelund Y, Maccarini PF, Stauffer PR and Jacobsen SK. Design of small-sized and low-cost front end to medical microwave radiometer. Progress in Electromagnetics Research Symposium Proc., 2010;932-6. PMCID: 4196692

[8] Birkelund Y, Klemetsen O, Jacobsen SK, Arunachalam K, Maccarini P, Stauffer PR. Vesicoureteral reflux in children: a phantom study of microwave heating and radiometric thermometry of pediatric bladder. IEEE Trans Biomed Eng. 2011; 58(11):3269-78. PMCID: 3281522.

[9] Arunachalam K, Maccarini PF, De Luca V, Tognolatti P, Bardati F, Snow $\mathrm{B}$, Stauffer PR. Detection of vesicoureteral reflux using microwave radiometry - system characterization with tissue phantoms. IEEE Trans Biomed Eng. 2011;58(6):1629-36. PMCID:3098321

[10] Snow BW, Arunachalam K, De Luca V, Maccarini PF , Klemetsen Ø, Birkelund,Y, Pysher TJ , and Stauffer PR. Non-invasive vesicoureteral reflux detection: Heating risk studies for a new device, J Ped Urol. 2011;7(6):624-30. PMCID:3178666.

[11] Stauffer PR, Maccarini PF, Arunachalam K, Salahi S, DeLuca V, Boico A, Klemetsen O, Birkelund Y, Jacobsen SK, Bardati F, Tognolatti P, Snow B. Microwave Radiometry for Non-Invasive Detection of Vesicoureteral Reflux (VUR) Following Bladder Warming. Proc. SPIE, TP Ryan ed. (SPIE Press, Bellingham WA). 2011;. 7901:OV1-11. PMCID: 3409575.

[12] Klemetsen O, Birkelund Y, Jacobsen SK, Maccarini PF and Stauffer PR. Design of medical radiometer front-end for improved performance. PIER B. 2011; 27: 289-306. PMCID:3138522.

[13] Stauffer PR and Maccarini PF. Evolution of antenna performance for applications in thermal medicine. 5th European Conference on Antennas and Propagation (EuCAP2011; Rome), 2011:3080-83. PMCID: 3593730.

[14] Rodrigues DB, Pereira JS, Limão-Vieira P, Stauffer PR, Maccarini PF. Study of the one dimensional and transient bioheat transfer equation: multilayer solution development and applications, Int J Heat Mass Tran. 2013;62(1):153-162. PMCID: 3913296

[15] Rodrigues DB, Maccarini PF, Salahi-Louie S, Colebeck E, Topsakal E, Pereira PMS, Limao-Vieira P, Stauffer PR. Numerical 3D modeling of heat transfer in human tissues for microwave radiometry monitoring of brown fat metabolism. Proc. SPIE, TP Ryan ed. (SPIE Press, Bellingham WA).. 2013;8584:OS1-12. PMCID 3824263.

[16] Stauffer PR, Rodriques DB, Salahi-Louie S, Topsakal E, Oliveira TR, Prakash A, D'Isidoro F, Reudink D, Snow BW, Maccarini PF. Stable Microwave Radiometry System for Long Term Monitoring of Deep Tissue Temperature. Proc. SPIE, TP Ryan ed. (SPIE Press, Bellingham WA).2013;OR1-11. PMCID: 3824255.

[17] Stauffer PR, Snow BW, Rodrigues DB, Salahi S, Oliveira TR, Reudink $\mathrm{D}$, and Maccarini PF. Non-invasive measurement of brain temperature with microwave radiometry: demonstration in a head phantom and clinical case. Neurorad J. 2014;27:3-12. PMCID: PMC4066964.

[18] ]Rodrigues, D.B., Maccarini, P.F., Salahi, S., Oliveira, T.R., Pereira, P.J., Limao-Vieira, P., Snow, B.W., Reudink, D. and Stauffer, P.R., Design and optimization of an ultra wideband and compact microwave antenna for radiometric monitoring of brain temperature. IEEE Trans Biomed Eng, 2014. 61(7): p. 2154-60. PMCID: 4193505 